\title{
A Comprehensive Profile of Antibiotic Resistance Genes in the Water Column of a Shallow-Sea Hydrothermal Vent Ecosystem
}

\author{
Jiangwei Li ${ }^{1,2,3}$, Lanping Zhang ${ }^{1,2,3}$, Yufang Li ${ }^{4}$, Keshao Liu ${ }^{5}$, Yongqin Liu ${ }^{5}$, Sijun Huang ${ }^{6,7}$, Furun Li ${ }^{6}$, \\ Chen-Tung A. Chen ${ }^{8}$, Yao Zhang ${ }^{9, *}$ (i) and Anyi Hu ${ }^{1,2,3, *(1)}$
}

check for

updates

Citation: Li, J.; Zhang, L.; Li, Y.; Liu, K.; Liu, Y.; Huang, S.; Li, F.; Chen, C.-T.A.; Zhang, Y.; Hu, A. A Comprehensive Profile of Antibiotic Resistance Genes in the Water Column of a Shallow-Sea Hydrothermal Vent Ecosystem. Sustainability 2022, 14, 1776. https://doi.org/10.3390/su14031776 Academic Editor: Paola Quatrini

Received: 8 December 2021 Accepted: 1 February 2022 Published: 4 February 2022 Publisher's Note: MDPI stays neutral with regard to jurisdictional claims in published maps and institutional affiliations.

Copyright: (C) 2022 by the authors. Licensee MDPI, Basel, Switzerland. This article is an open access article distributed under the terms and conditions of the Creative Commons Attribution (CC BY) license (https:// creativecommons.org/licenses/by/ $4.0 /)$.
1 CAS Key Laboratory of Urban Pollutant Conversion, Institute of Urban Environment, Chinese Academy of Sciences, Xiamen 361021, China; jwli@iue.ac.cn (J.L.); lpzhang@iue.ac.cn (L.Z.)

2 University of Chinese Academy of Sciences, Beijing 100049, China

3 Fujian Key Laboratory of Watershed Ecology, Institute of Urban Environment, Chinese Academy of Sciences, Xiamen 361021, China

4 Fisheries College, Jimei University, Xiamen 361021, China; 202161000079@jmu.edu.cn

5 Key Laboratory of Tibetan Environment Changes and Land Surface Processes, Institute of Tibetan Plateau Research, Chinese Academy of Sciences, Beijing 100101, China; liukeshao@itpcas.ac.cn (K.L.); yqliu@itpcas.ac.cn (Y.L.)

6 CAS Key Laboratory of Tropical Marine Bio-Resources and Ecology, South China Sea Institute of Oceanology, Chinese Academy of Sciences, Guangzhou 510301, China; huangsijun@scsio.ac.cn (S.H.); lifurun18@mails.ucas.ac.cn (F.L.)

7 Southern Marine Science and Engineering Guangdong Laboratory, Guangzhou 511458, China

8 Department of Oceanography, National Sun Yat-sen University, Kaohsiung 80424, Taiwan; ctchen@faculty.nsysu.edu.tw

9 State Key Laboratory of Marine Environmental Science and College of Ocean and Earth Sciences, Xiamen University, Xiamen 361102, China

* Correspondence: yaozhang@xmu.edu.cn (Y.Z.); ayhu@iue.ac.cn (A.H.)

Abstract: Antibiotic resistance genes (ARGs) became an emerging contaminant, and were found to accumulate in natural and man-made environments. A comprehensive understanding of the diversity and abundance of ARGs in pristine environments is critical for defining the baseline levels of environmental ARGs. However, there is limited information available on the ARG profiles of pristine environments, especially for shallow-sea hydrothermal vents ecosystems. Here, we combined $16 \mathrm{~S}$ rRNA gene full-length amplicon sequencing and high-throughput quantitative PCR (HT-qPCR) to study the bacterial communities, and ARG abundance and diversity in the shallow-sea hydrothermal vent ecosystem of the Kueishantao Islet. The results of the $16 \mathrm{~S}$ rRNA gene amplicon sequencing showed that several sulfur-cycling related bacterial genera, including Thiomicrorhabdus, Thioreductor, Sulfurovum, Sulfurimonas and Lebetimonas, dominated in the water column of the shallow-sea system. Temperature was the significant factor shaping the bacterial communities. The results of HT-qPCR analysis showed that the Kueishantao shallow-sea system harbored the lowest diversity (average 10 ARG subtypes) and abundance (average $1.0 \times 10^{-3}$ copy per bacterial cell) of ARGs compared with other pristine (i.e., Tibet lake sediments, marine water and sediments) and anthropogenicdisturbed (i.e., drinking water reservoirs, urban ponds and wastewater treatment plants) environments. Procrustes analysis demonstrated a concordant pattern between the compositions of bacterial communities and ARGs in the shallow-sea system, while variation partition analysis revealed that the shared effects of physicochemical and bacterial communities explained $>80 \%$ of the variation in the composition of ARGs. These results suggest that the vent bacterial communities and local environmental factors played an important role in shaping the distribution of the ARG profiles. Our study provides the first comprehensive overview of the background level of ARGs in a shallow-sea hydrothermal vent ecosystem.

Keywords: shallow-sea hydrothermal vent ecosystem; antibiotic resistance genes; mobile genetic elements; vertical and horizontal genetic transfer; high-throughput quantitative PCR; 16S rRNA gene full-length amplicon sequencing 


\section{Introduction}

Antibiotic resistance genes (ARGs) are a group of ancient genetic elements, and have been recovered from 30,000-year-old Beringian permafrost sediments [1,2]. However, due to the abuse of antibiotics in human and animal therapy and livestock, ARGs have become one of the emerging contaminants of concern in the environment and pose a great threat to the health of human beings [3,4]. The World Health Organization estimated that antimicrobial resistance-induced diseases will cause more than 10 million deaths per year by 2050 [5]. The application of high-throughput molecular technologies in recent years, such as shotgun metagenomic sequencing and high-throughput quantitative PCR (HT-qPCR), significantly enhance our ability to get a comprehensive profile of an antibiotic resistome in various environments, but also identify the associated regulating factors [6-10]. Mounting evidence suggests that the biotic processes, including the vertical genetic transfer (VGT) and horizontal genetic transfer (HGT), are the primary mechanisms controlling the proliferation and dissemination of ARGs [11]. The former and latter are mainly mediated by microbial communities and mobile genetic elements (MGEs), respectively [12]. In particular, the HGT could lead to the random transfer of ARGs between fecal and environmental microbes [13,14], which were proposed as the main cause for ARG pollution in the environments [12]. For example, due to the continuous inputs of domestic sewage, wastewater treatment plants (WWTPs) became hotspots of the dissemination of ARGs $[15,16]$. However, the VGT was also found to be responsible for shaping the ARG profiles in 18 agricultural and grassland soils [17], the sediments of a freshwater reservoir [18] and a coastal lagoon [19]. In addition, abiotic factors, such as chemical pollutants (non-antibiotic pharmaceuticals and metalloids etc.), may cause the spread of ARGs through the promotion of the HGT or co-selection processes [8,11]. Although a plethora of studies have revealed the biogeographic distribution of ARGs in various anthropogenicdisturbed environments [20-23], there is limited information about the ARG profiles in pristine habitats, especially for the shallow-sea hydrothermal vents, which is essential for defining the baseline level of environmental ARGs.

The shallow-sea hydrothermal vents represent a unique pristine ecosystem, occurring near active coastal or submarine volcanoes with depths of less than $200 \mathrm{~m}[24,25]$. Unlike their deep counterparts, the plume fluids of shallow-sea vents can diffuse across the whole water column rather than being restricted to a nearby bottom water zone [26]. Therefore, the whole water column of such ecosystems contains substantial concentrations of reductive chemical compounds, such as $\mathrm{H}_{2} \mathrm{~S}, \mathrm{CH}_{4} \mathrm{H}_{2}$ and $\mathrm{NH}_{3}$, etc. [25,27-29]. Diverse sulfur-oxidizing (e.g., Sulfurimonas and Sulfurovum) and reducing (e.g., Nautilia, Thioglobus, Thiomicrorhabdus and Thiomicrospira) chemoautotrophs have been found as dominant microbial populations in the shallow-sea ecosystems [25,30,31]. However, due to sunlight available across the water column, photoautotrophs such as cyanobacteria were also a critical component of bacterial communities of shallow-sea ecosystems [24,27], contributing a certain part of the primary production [32]. In addition, microorganisms living in hydrothermal vents may tend to enrich various stress tolerance genes via HGT, which could be helpful for them to adapt to harsh environmental conditions (e.g., high temperatures and toxic gases) [33]. It has been suggested that ARGs are beneficial for thermal microorganisms not only in terms of coping with selective environmental stresses [34], but also for competing with other species [35]. Some prior investigations have shown that ARGs were ubiquitous in diverse pristine environments, including plateau lake sediments [36], polar soils [37], hot springs [38,39] and deep-sea hydrothermal vents [35]; however, it is difficult to compare the results of different studies as different methodologies were used for ARG analysis in different studies. Moreover, very limited information is available on the diversity and abundance of ARGs in shallow-sea hydrothermal vent ecosystems.

Here, we employed the 16S rRNA gene full-length amplicon sequencing and HT-qPCR approaches to explore the biogeographic distribution pattern of bacterial communities, and ARG abundance and diversity in the water column of the shallow-sea hydrothermal vent ecosystem of Kueishantao Islet, respectively. A cluster of shallow-sea vents ( $<30 \mathrm{~m}$ 
in depth) have been found around $1 \mathrm{~km}$ east of Kueishantao Islet $\left(24.83^{\circ} \mathrm{N}, 121.96^{\circ} \mathrm{E}\right.$; Figure 1) [24]. Because the Kueishantao ecosystem is far away from human activities, and poses strong impacts on the nearby water column [24,27], it is an ideal research object to explore the baseline levels of environmental ARGs. We aimed to (i) explore the background level of ARGs in a shallow-sea hydrothermal vent ecosystem; (ii) explore the spatial distribution of the ARGs and distinguish the relative importance of VGT and HGT on the ARG profile. To compare the ARG profile of the shallow-sea hydrothermal vent ecosystem with other environments, the HT-qPCR results of $>200$ samples from multiple pristine (i.e., marine water and sediments, and Tibet lake sediments) and anthropogenic-disturbed (i.e., drinking water reservoirs, urban ponds and WWTP-related samples) environments were incorporated into the analysis. We hypothesized that the shallow-sea hydrothermal vent ecosystem should harbor the lowest level of ARGs due to the rare and strong influences from human activities and vent plume fluids, respectively, while both HGT and VGT play an important role in controlling the ARG profiles. Taken together, this study will enhance our understanding on the environmental background level of the ARGs, which could be helpful for identifying the baseline levels of environmental ARGs.

A

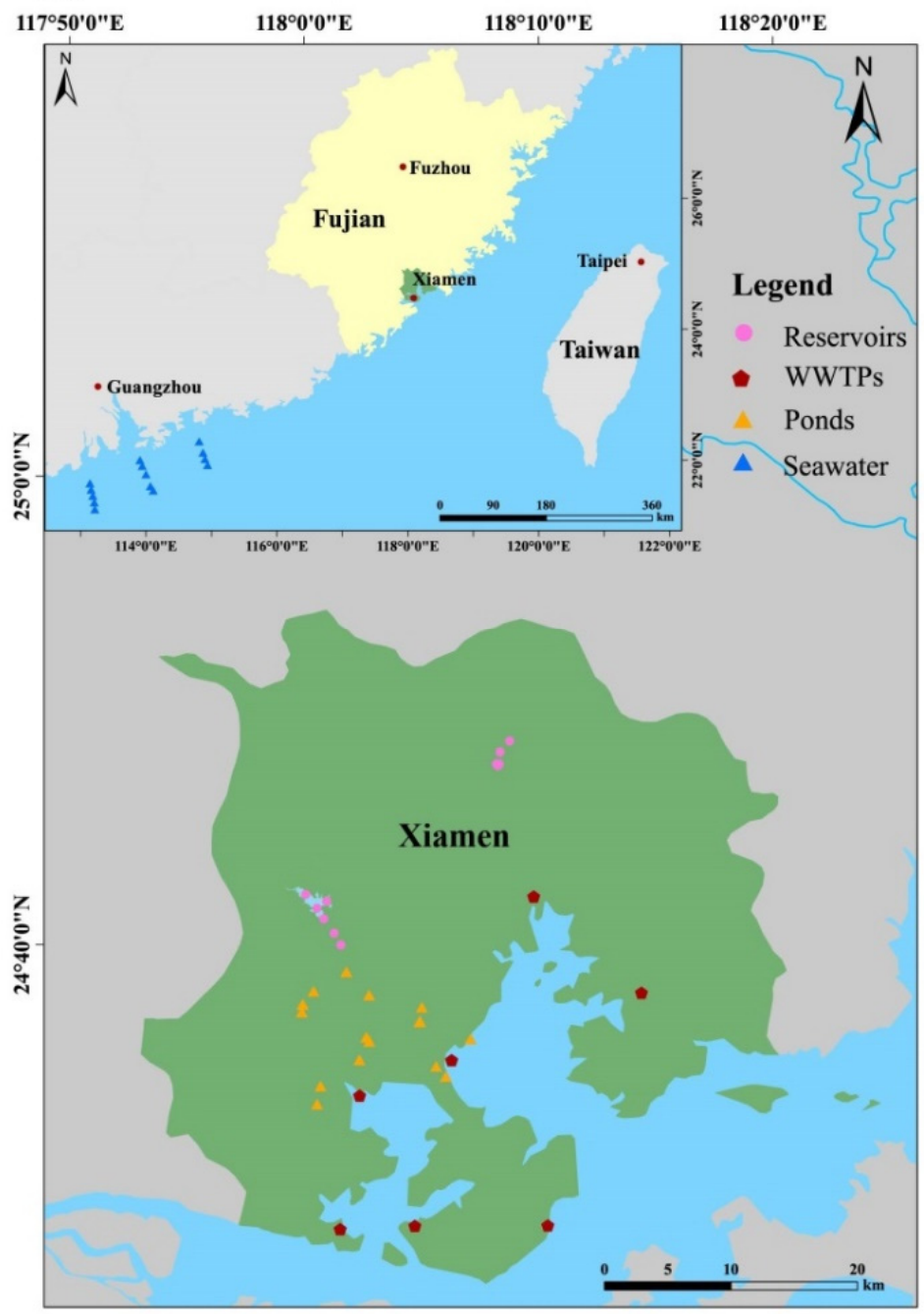

B
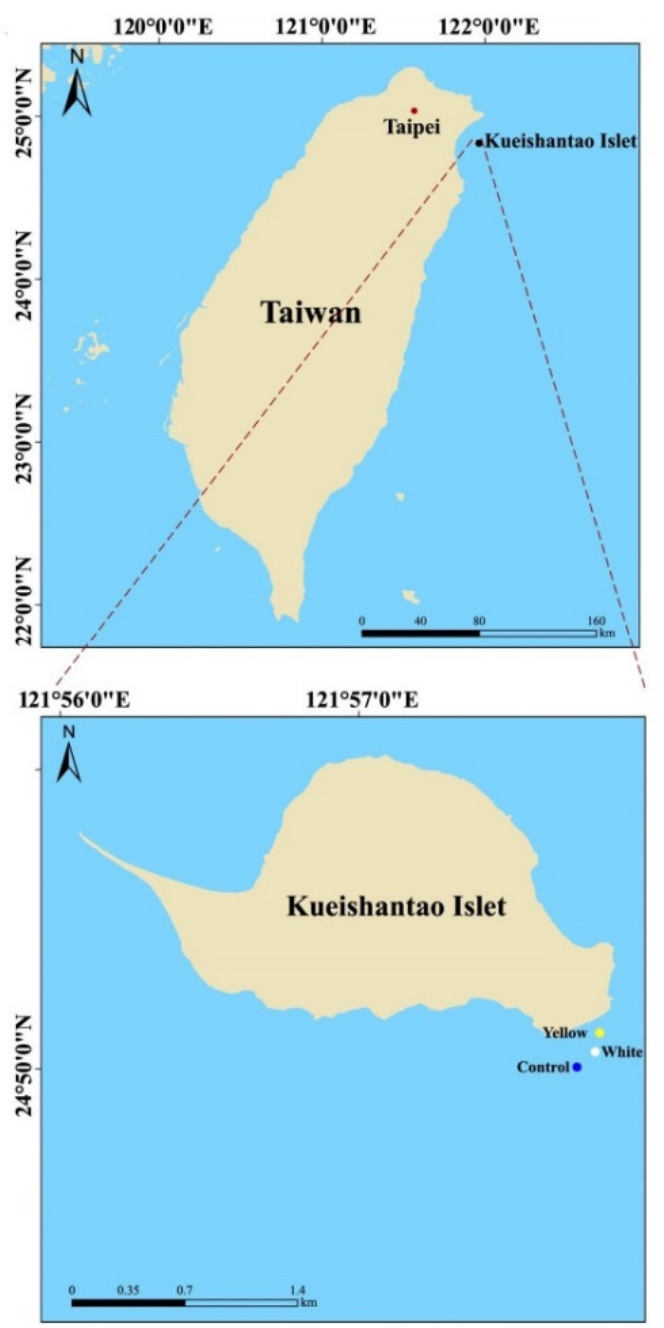

Figure 1. Sampling sites of drinking water reservoirs, urban ponds and WWTPs in Xiamen. Sampling sites for seawater sampling are also shown (A); the geographic location of the Kueishantao Islet, and the sampling location of the Yellow vent, White vent and Control sites (B). 


\section{Materials and Methods}

\subsection{Sampling Design, Collection and Physicochemical Analysis}

Two shallow-sea hydrothermal vents (i.e., White $\left(24.83455^{\circ} \mathrm{N}, 121.96339^{\circ} \mathrm{E}\right)$ and Yellow $\left(24.83560^{\circ} \mathrm{N}, 121.96339^{\circ} \mathrm{E}\right)$ vents) are located within $1 \mathrm{~km}$ east of Kueishantao Islet of Yilan County (Figure 1B). Previous studies have performed intensive investigations on this ecosystem, and found the water column contains moderate amount of $\mathrm{H}_{2}$ and $\mathrm{CH}_{4}$, while thermal reductive reactions of seawater and sulfate radicals could generate trace $\mathrm{H}_{2} \mathrm{~S}[24,30]$. To investigate the biogeographic distribution of ARGs in the shallow-sea ecosystem, a total of eight water samples were collected from the surface $(0.5 \mathrm{~m})$, middle $(5 \mathrm{~m})$ and bottom (13 and $8 \mathrm{~m}$ ) layers for the White site (WS, WM and WB, respectively) and Yellow site (YS, $\mathrm{YM}$ and $\mathrm{YB}$, respectively), as well as hydrothermal fluids of the White vents (WH) and Yellow vents (YH) during May 2019. In addition, three water samples (CS, CM and CB) were collected from surface $(0.5 \mathrm{~m})$, middle $(5 \mathrm{~m})$ and bottom $(10 \mathrm{~m})$ layers of the Control site $\left(24.83370^{\circ} \mathrm{N}, 121.96212^{\circ} \mathrm{E}, 160 \mathrm{~m}\right.$ far from the White site). All water samples were collected using sealed, custom made, polyvinylchloride tubes by scuba divers. The permits for field sampling were obtained from the Coast Guard Administration of Taiwan and the Fisheries Management Office of the Yilan County.

The physicochemical parameters of the water samples of the shallow-sea ecosystem, including temperature, salinity, $\mathrm{pH}$, dissolved oxygen (DO), chlorophyll-a (Chla), ammonia $\left(\mathrm{NH}_{4}-\mathrm{N}\right)$, nitrite $\left(\mathrm{NO}_{2}-\mathrm{N}\right)$, nitrate $\left(\mathrm{NO}_{3}-\mathrm{N}\right)$, silicate $\left(\mathrm{SiO}_{2}-\mathrm{Si}\right)$, dissolved inorganic carbon (DIC), dissolved organic carbon (DOC) and $\mathrm{CH}_{4}$, were determined either in situ or in lab as described elsewise [30]. The detailed information was summarized in Table S1, Supplementary Materials. For molecular analysis, around $2.5 \mathrm{~L}$ water samples were filtered by $0.22 \mu \mathrm{m}$ Sterivex-GP filters (Millipore, MA, USA) at a pressure $<0.03 \mathrm{MPa}$ on board. After filtration, the filters were immediately frozen by liquid nitrogen, and then stored at $-80^{\circ} \mathrm{C}$ in a lab until further analysis.

To compare the abundance and diversity of the ARGs of the shallow-sea hydrothermal vent ecosystem with other pristine ecosystems, multiple datasets from Tibet lake sediments (16 samples), marine surface water (14) and sediments (14) of the northern South China Sea were incorporated into the analysis (Figure 1 and Figure S1). Moreover, several datasets from anthropogenic-disturbed environments, such as the drinking water reservoirs (12), urban ponds (16) and WWTPs (influents (WWTP_IF, 49), activate sludge (WWTP_AS, 49) and effluents (WWTP_EF, 49)) of a coastal city (Xiamen), China, were also included (Figure 1A). The drinking water reservoirs could represent relatively well-managed water bodies in urban environments, while WWTPs and urban ponds were reported as the hotspots for the dissemination of ARGs [40]. The water samples mentioned here were processed using the same filtration method as described above. Due to the different regulations between Taiwan and the mainland, China, we could only collect samples from anthropogenic-disturbed environments in Xiamen, China. Some (72 of 219 samples) of the above datasets have been shown in our previous studies $[19,41]$.

\subsection{DNA Extraction, $16 \mathrm{~S}$ rRNA Gene Full-Length High-Throughput Sequencing and Sequence Analysis}

Environmental DNA was extracted from all the samples of this study using the FastDNA SPIN Kit for Soil (Qbiogene-MP Biomedicals, Irvine, CA, USA) [42], and quantified by using the Qubit 2.0 fluorometer with Qubit dsDNA BR assay kit (Life Technologies, Grand Island, NY, USA). The full length of 16S rRNA genes were amplified by using the primer pair 27F (5'-AGA GTT TGA TCC TGG CTC AG-3') and 1492R (5'-GNT ACC TTG TTA CGA CTT-3'). PCR reactions were performed in $25 \mu \mathrm{L}$ in triplicate containing $5 \mu \mathrm{L}$ TransStart FastPfu Buffer $(5 \times), 2 \mu \mathrm{L}$ dNTPs $(2.5 \mathrm{mM}), 0.5 \mu \mathrm{L}$ TransStart FastPfu DNA Polymerase (2.5 units $/ \mu \mathrm{L}$, TransGen Biotech, Beijing, China) and $0.4 \mu \mathrm{M}$ of forward and reverse primers, and $10 \mathrm{ng}$ of template DNA. The PCR amplification cycle was set as $95^{\circ} \mathrm{C}$ for $5 \mathrm{~min}$ for initial denaturation, followed by 30 cycles of $95^{\circ} \mathrm{C}$ for $30 \mathrm{~s}, 55^{\circ} \mathrm{C}$ for $45 \mathrm{~s}$, and $72{ }^{\circ} \mathrm{C}$ for $90 \mathrm{~s}$, and followed by a final extension at $72{ }^{\circ} \mathrm{C}$ for $10 \mathrm{~min}$. PCR reactions 
were performed for each sample, and the PCR products were purified using the QIAquick ${ }^{\circledR}$ Gel Extraction Kit (Qiagen, Santa Clarita, CA, USA). Sequencing libraries were generated using SMRTbell ${ }^{\mathrm{TM}}$ Template Prep Kit (Pacific Biosciences, Menlo Park, CA, USA) following the manufacturer's recommendations, and then sequenced on a PacBio Sequel platform (Beijing Nuohe Zhiyuan Technology Co., Ltd., Beijing, China). Due to low DNA concentration, no valid sequences were obtained from YB and YH samples. The 16S rRNA gene sequencing data were deposited into the NCBI short reads archive (SRA) database under BioProject numbers PRJNA799604.

The full-length 16S rRNA gene sequences were quality trimmed by using PacBio SMRT portal v2.3.0. Briefly, sequences not meeting the following criteria were discarded: (i) a minimum pass $\geq 3$; (ii) a minimum predicted accuracy $\geq 90 \%$; (iii) a sequence length $<1340 \mathrm{bp}$ or $>1640 \mathrm{bp}$. After quality control, an average of 23,029 high-quality reads per sample (average $83.2 \%$ of raw reads) remained. The high-quality reads were used for chimerachecking and clustered into operational taxonomic units (OTUs) at the cutoff of $97 \%$ identity using UPARSE v7.0.1001 [43]. The representative sequence of each OTU was classified by using the RDP classifier with the SILVA database v138 [44] at a confidence threshold of $80 \%$. $\alpha$ - and $\beta$-diversity of the bacterial communities were analyzed using R package phyloseq [45].

\subsection{HT-qPCR Analysis of ARGs}

The occurrence and abundance of ARGs were determined on a high-throughput quantitative PCR system (SmartChip Real-time PCR, Warfergen Inc., Fremont, CA, USA) with 296 primer pairs described previously [6]. Among those primer pairs, 285 and 10 primer sets targeted eight major ARG types and two MGE types (i.e., eight transposase genes and two integrase genes), respectively. In addition, one primer set targeting $16 \mathrm{~S}$ rRNA genes was also included [6]. Numerous previous studies have employed this method to study the ARG profiles in diverse aquatic environments [6,8,41]. Amplification was conducted in a $100 \mathrm{~nL}$ reaction system containing $1 \times$ LightCycler $^{\circledR} 480$ SYBR Green I Master Mix (Roche, UK), $5 \mathrm{ng} / \mu \mathrm{L}$ of template DNA, $1 \mathrm{ng} / \mu \mathrm{L}$ bovine serum albumin, and each forward and reverse primer. The qPCR amplification cycle was set as $95^{\circ} \mathrm{C}$ for $10 \mathrm{~min}$ for initial denaturation, followed by 40 cycles of $95{ }^{\circ} \mathrm{C}$ for $30 \mathrm{~s}$ and $60{ }^{\circ} \mathrm{C}$ for $30 \mathrm{~s}$. The HT-qPCR data were processed by using SmartChip qPCR software $[19,41]$. The previous study based on the Ribosomal RNA Operon Copy Number Database showed that each bacterial cell contains an average of four copy numbers of $16 S$ rRNA genes [6]. Thus, the approximate bacterial cells in a community can be calculated as described previously [41].

$$
\text { Cells }=\frac{16 \mathrm{Sabu}}{4}
$$

where 'Cells' indicate the approximate bacterial cells in a community, '16Sabu' is the absolute abundance of 16S rRNA genes in a community, and ' 4 ' indicates the average copy number of $16 \mathrm{~S}$ rRNA genes in a bacterial cell.

Then, the normalized abundances (gene copies per bacteria cell) of ARGs can be calculated as follows:

$$
\text { ARGnor }=\frac{\text { ARGabu }}{\text { BacCells }}
$$

where 'ARGnor' indicates the normalized abundances of ARGs in a sample, and 'ARGabu' is the abundance of ARGs in a sample from HT-qPCR analysis.

Although the above transformation might induce some biases on estimating the ARG abundance, it could facilitate us to compare our results with those from previous studies. Due to low positive yield of HT-qPCR analysis, samples from the bottom layers (i.e., WB and $\mathrm{YB}$ ) and vents (i.e., $\mathrm{WH}$ and $\mathrm{YH}$ ) of the White and Yellow sites were excluded from the further analysis for ARGs.

The absolute abundance of $16 \mathrm{~S}$ rRNA genes was determined by using the SYBR ${ }^{\circledR}$ Green chemistry on a conventional quantitative PCR system (LightCycler ${ }^{\circledR} 480$ instrument, 
Roche, Switzerland) [19]. Triplicate reactions were performed for each sample in HT-qPCR or conventional qPCR assays, and negative no-template controls were also included in each qPCR plate.

\subsection{Statistical Analysis}

The relationship between the absolute abundance of ARGs and MGEs was determined by using Spearman's correlation test. Non-metric multidimensional scaling (NMDS) analysis based on the Bray-Curtis distance was employed to determine the $\beta$-diversity pattern of bacterial communities or ARGs [42]. The difference in the composition of ARGs among different locations (i.e., Control, White and Yellow sites) was determined by using the analysis of similarity (ANOSIM) and permutational multivariate analysis of variance (Adonis). To address the multicollinearity issue, the variation inflation factor (VIF) analysis was used to exclude the environmental variables with high collinearity (VIF > 5) by using "vifstep" function in R package usdm (Naimi et al., 2014) [46]. Then, the relationship between physicochemical variables and the $\beta$-diversity of bacteria or ARGs was determined by using the "envfit" function in R package vegan [47]. The variation partitioning analysis (VPA) was used to determine the pure effects of the physicochemical variables, MGEs (the absolute and normalized abundances of MGEs) and bacterial communities (the first two axes of PCoA ordination) on the composition of ARGs [41]. The significant response variables in explaining the $\beta$-diversity variation of ARGs were identified by using forward selection with the 'ordiR2step' function in R package vegan [47]. The statistical analysis and visualization were conducted using R v4.10 with the packages ggplot2 [48] and ComplexHeatmap [49].

\section{Results and Discussion}

\subsection{Profiling ARGs in Multiple Pristine and Anthropogenic-Disturbed Environments}

A total of 250 ARG subtypes, which belong to eight major ARG types (i.e., aminoglycoside, $\beta$-lactamase, chloramphenicol, Macrolide-Lincosamie-Streptogamin B (MLSB), multidrug, sulfonamide, tetracycline and vancomycin resistance genes), occurred in the 232 samples from multiple pristine and anthropogenic-disturbed environments in this study. The average number of ARGs detected in different environments ranged from 85 to 10 subtypes per sample, decreasing in the following order: WWTP_IF $>$ WWTP_EF > ponds $>$ WWTP_AS $>$ marine sediment $>$ seawater $>$ reservoirs $>$ Tibet lake sediment $>$ shallow-sea hydrothermal vents (Figure 1A). The average normalized abundance of ARGs in different environments ranged from 1.95 to $1.0 \times 10^{-3}$ copies per bacterial cell per sample, and showed a slightly different order pattern compared with the occurrence of the ARGs (Figure 1B). For example, the pond samples contained the second-highest average normalized abundance of ARGs (1.40), which may be attributed to the sewage pollution [41]. In addition, the average normalized abundance of ARGs in the reservoirs (0.07) was higher than those of the seawater (0.01) and marine sediments (0.05). The low ARG abundance detected in the Tibet lake sediments, marine water and sediments are expected given the relatively low human disturbance in those areas. Similar findings were obtained from several previous studies. For instance, Chen et al. (2016) and Wang et al. (2021) have found that the sediments of the northern South China Sea and Tibet saline lakes entrained significantly lower concentrations of ARGs than those from anthropogenic-disturbed estuarine and urban lagoon sediments, respectively $[19,36]$.

PCoA ordination of the composition of ARGs demonstrated that all samples tended to cluster based on their environmental sources (Figure 2A), providing further evidence that the $\beta$-diversity of ARGs harbors a habitat-specific biogeographic distribution pattern to their host (bacterial) communities. In fact, the first axis of the PCoA ordination indicated a clear anthropogenic-disturbed gradient showing the shift of the composition of ARGs from highly human-disturbed (i.e., WWTP-related samples) to pristine environments (i.e., marine and Tibet lake sediment samples). We further explored the $\beta$-diversity pattern of the ARGs from a marine environment only, and a habitat-specific distribution of marine 
ARGs was also observed (Figure 3B). In other words, the samples from the shallow-sea ecosystem, marine water and sediments were apt to cluster together separately. ANOSIM and Adonis tests indicated that different environments harbored distinct ARG compositions $(p<0.001)$, providing further support for the results of PCoA analysis. These results are consistent with Ma et al. (2017), who showed the composition of ARGs of the drinking water, river water, sediments, WWTPs and livestock wastes were different from each other [50], implying that local bacterial communities and contemporary environmental factors may shape the composition of ARGs [9]. However, due to the large distance $(>1000 \mathrm{~km})$ between the Kueishantao shallow-sea ecosystem and the studied area in the South China Sea (Figure 1), it is hard to exclude the influences of geographic isolation on the composition of marine ARGs [41,51].

Environment

- Shallow hydrothermal ven

- Seawater

Marine sediment

Tibet lake sediment

- Reservoir

- Pond

- WWTP IF

WWTP AS

WWTP_EF
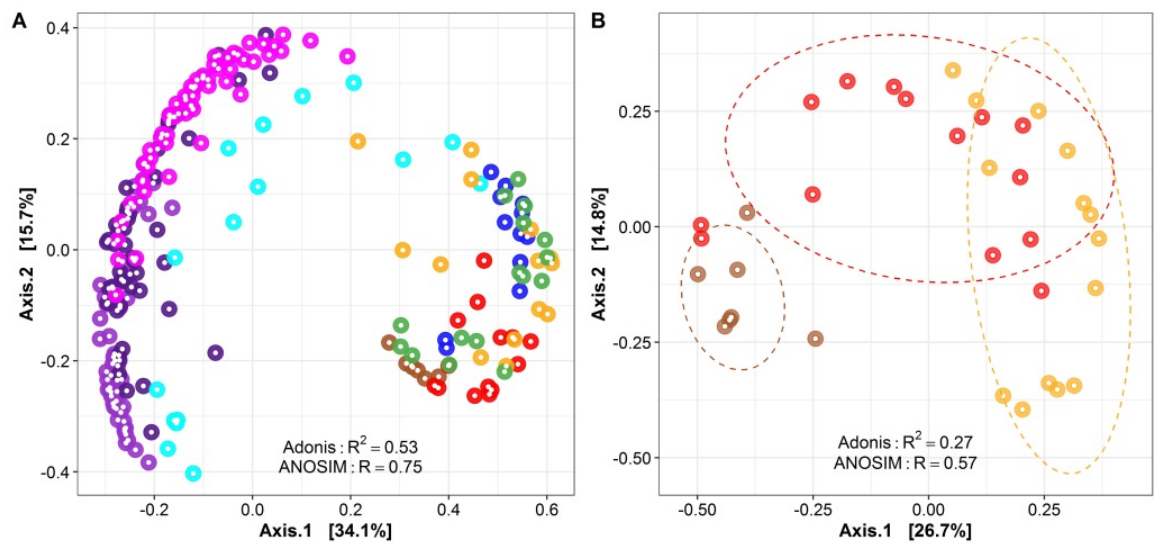

Figure 2. PCoA analyses demonstrating the $\beta$-diversity pattern of ARGs from different environments (see the legend of Figure 1 for the detail description about each environment) (A) and marine environments (i.e., shallow-sea hydrothermal vents, marine water and sediments of the northern South China Sea) (B). Ellipses $90 \%$ were constructed using the 'ordiellipse' function of vegan package to illustrate the samples from different marine habitats.
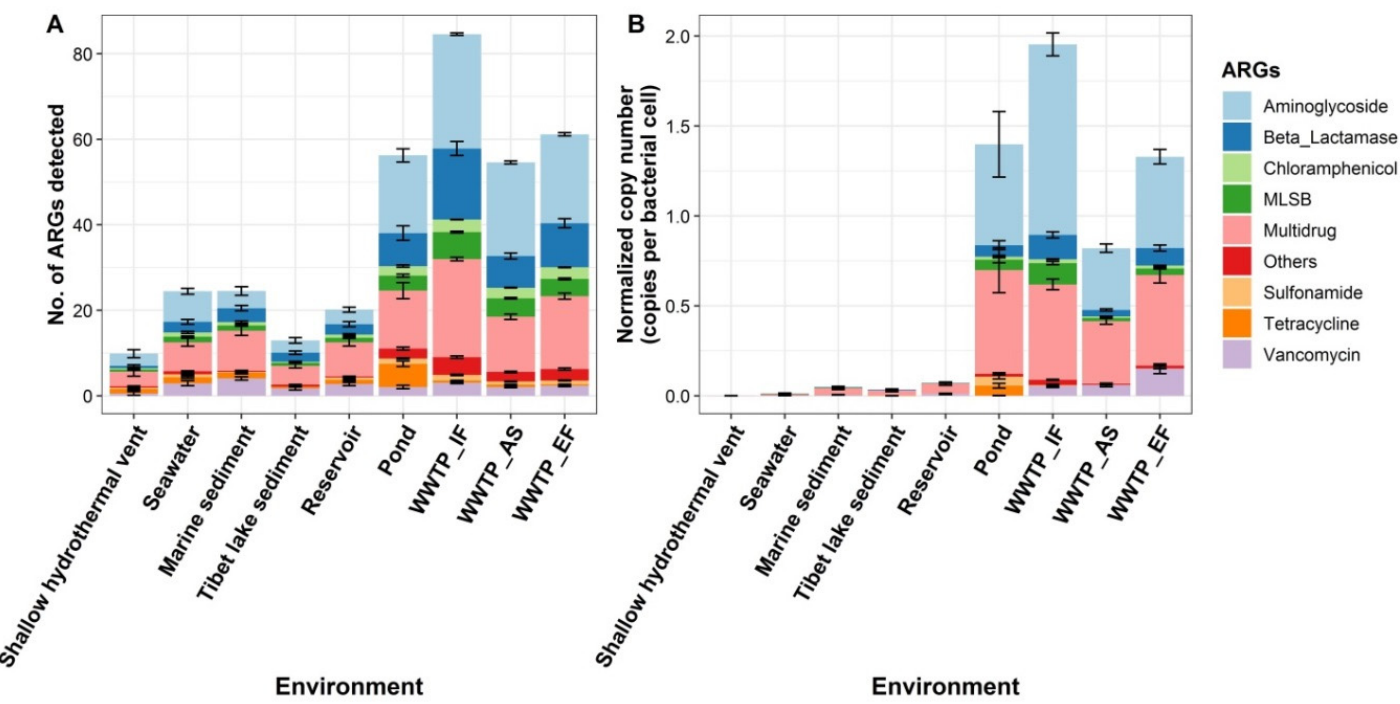

Figure 3. Diversity (A) and normalized abundance (B) of ARGs in multiple pristine (i.e., shallow-sea hydrothermal vent, Tibet lake sediment, and marine water and sediment of South China Sea) and anthropogenic-disturbed (i.e., drinking water reservoir, urban pond, and influent, activated sludge and effluent of WWTPs of Xiamen city) environments. ARG subtypes are classified into eight types, including aminoglycosides, $\beta$-lactamase, chloramphenicol, MLSB, multidrug, sulfonamide, tetracycline, and vancomycin resistance genes. Others indicate unclassified resistance genes. A part of the samples (72 of 219) from other environments have been shown in our previous studies [19,41]. 


\subsection{Diversity and Abundance of ARGs in the Shallow-Sea Hydrothermal Vent Ecosystem}

For the investigated shallow-sea hydrothermal vent ecosystem, a total of 56 ARG subtypes were detected in seven samples (Figure 4A), with the Yellow and White samples harboring the highest and lowest number of ARGs, respectively. Antibiotic deactivation and efflux pump were the dominant resistance mechanisms of ARGs in the shallow-sea ecosystem, except for the surface sample of the White site (i.e., WS) (Figure 4B). It has been suggested that the efflux pump may be beneficial for bacteria in terms of resisting environmental stresses $[2,35,37]$. In addition, a metagenomic study showed that the deactivation of aminoglycoside, chloramphenicol and $\beta$-lactamase antibiotics was one of the common resistance mechanisms in remote pristine Antarctic soils [2].
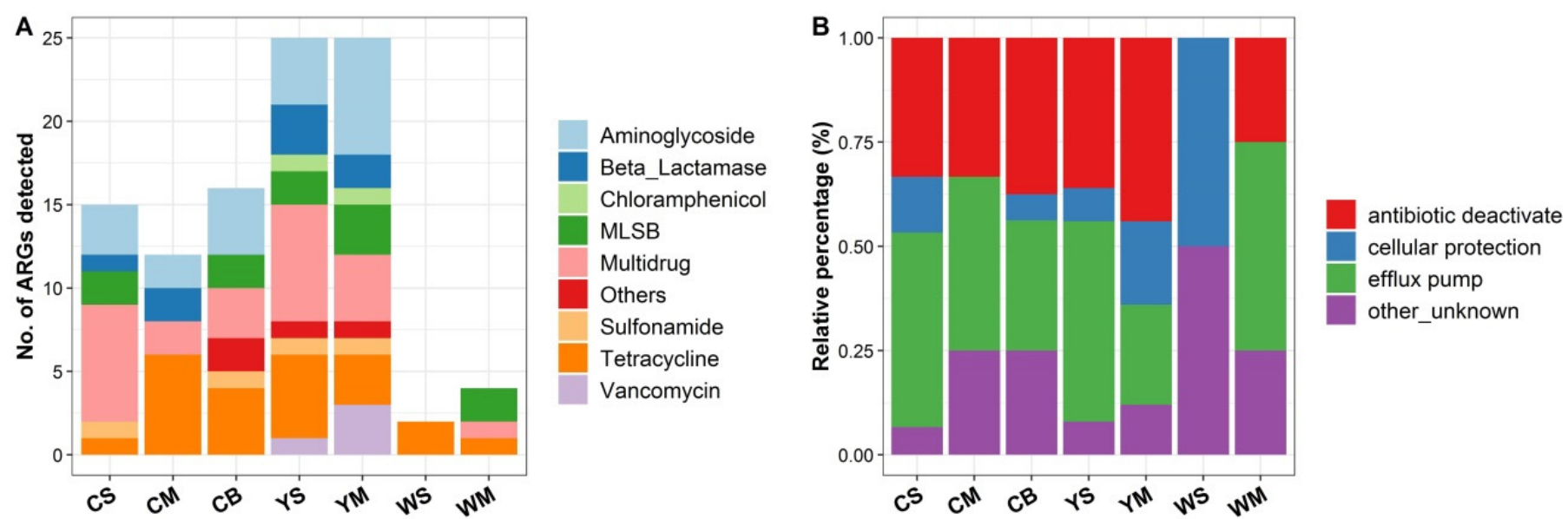

Figure 4. Diversity (A) and resistance mechanisms (B) of ARGs in the Kueishantao shallow-sea ecosystem. The water samples were collected from the surface (S), middle (M) and bottom (B) layers of the Control site $(\mathrm{C})$, Yellow $(\mathrm{Y})$ and White $(\mathrm{W})$ vent sites.

The quantitative analysis demonstrated that the absolute and normalized abundances of ARGs in the Control site were higher than those from the Yellow and White sites, except that the WM sample had the highest absolute abundance of ARGs ( 2500 copies/mL). Notably, the normalized abundance of ARGs increased along the depth in each site, while no similar pattern was observed for the absolute abundance of ARGs (Figure 5). One possible reason for this pattern is that the bacterial species lived closer to the vents may be apt to harbor ARGs (higher normalized abundance), which could be helpful for them to fight against harsh environmental stresses or compete with other bacteria [35]. However, due to the lack of positive results from the bottom layer and vent samples, further studies are needed to test this speculation.

\subsection{Bacterial Community Compositions of the Shallow-Sea Thermal Vent Ecosystem}

This Taxonomic assignment indicated that Gammaproteobacteria, Epsilonproteobacteria, Alphaproteobacteria, and Cyanobacteria were the most abundant bacterial phyla in the water column of the Kueishantao shallow-sea ecosystem, accounting for 68.1, $11.8,8.7$ and $3.9 \%$ of the total bacterial communities, respectively. At the genus level, Thiomicrorhabdus (Gammaproteobacteria), Thioreductor (Epsilonproteobacteria), Sulfurovum (Epsilonproteobacteria), Sulfurimonas (Epsilonproteobacteria), and Lebetimonas (Epsilonproteobacteria) were the most abundant genera, accounting for $66.9,8.2,1.2,1.0$ and $1.0 \%$ of the total bacterial communities (Figure 6A). Those genera were well reported as dominant taxa in both shallow- and deep-sea hydrothermal vent ecosystems [31,52-54], and were involved in carbon (e.g., $\mathrm{CO}_{2}$ fixation), sulfur (sulfur oxidization and sulfate reduction) and hydrogen (hydrogen oxidization) cycling. Liu et al. (2020) have isolated a novel pure Thiomicrorhabdus strain (Thiomicrorhabdus indica) from a deep-sea hydrothermal vent, 
and found it can use carbon dioxide source, and thiosulfate, sulfide, elemental sulfur or tetrathionate as the sole carbon and energy source, respectively [55].
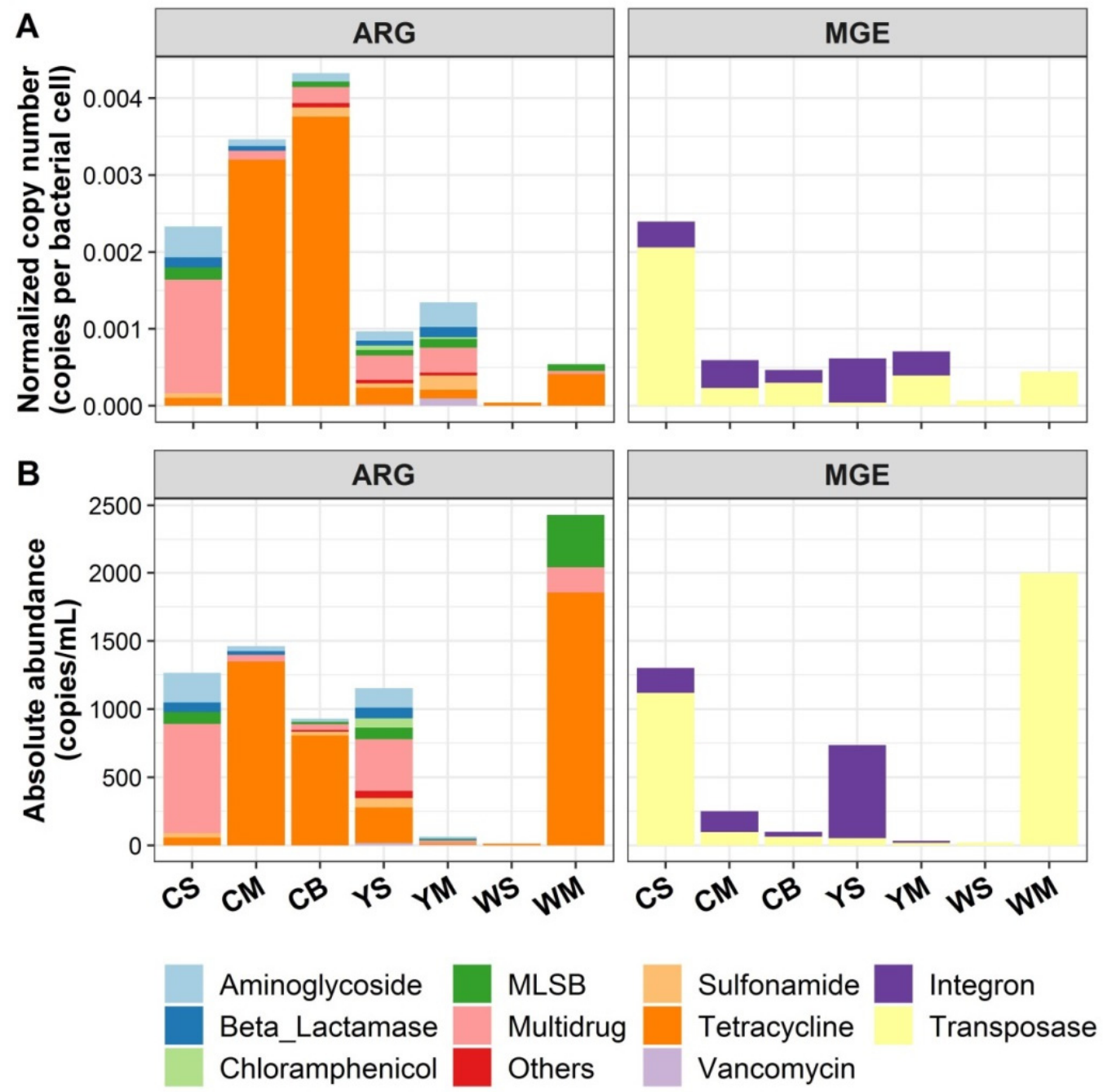

Figure 5. The normalized (A) and absolute abundances (B) of ARGs and MGEs in the Kueishantao shallow-sea ecosystem. The water samples were collected from the surface (S), middle (M) and bottom (B) layers of the Control site (C), Yellow (Y) and White (W) vent sites.

NMDS analysis indicated that the bacterial communities from the Control, White and Yellow sites tended to cluster separately from each other. It is notable that the White vent sample (WH) was located away from other samples (Figure 6B), implying the unique bacterial communities posed by the hydrothermal vents. Indeed, several genera Balnearium, Hydrogenimonas, Lebetimonas and Thioreductor had higher abundance in the White vent (i.e., WH) compared with other samples, suggesting they adapted to high temperature, low $\mathrm{pH}$, low DO saturation and high concentration of $\mathrm{H}_{2}$ (Table S1). Mounting evidence suggests that the species belonged to genera, which play an important role in sulfur and hydrogen cycling, live as strict to facultative anaerobes in high-temperature environments, and can fix $\mathrm{CO}_{2}$ via reductive tricarboxylic acid cycle [56]. In support of these patterns, the envfit analysis revealed that temperature was the significant factor shaping the $\beta$-diversity pattern of the bacterial communities $\left(\mathrm{r}^{2}=0.55, p<0.05\right)$ (Figure $\left.6 \mathrm{~B}\right)$. 

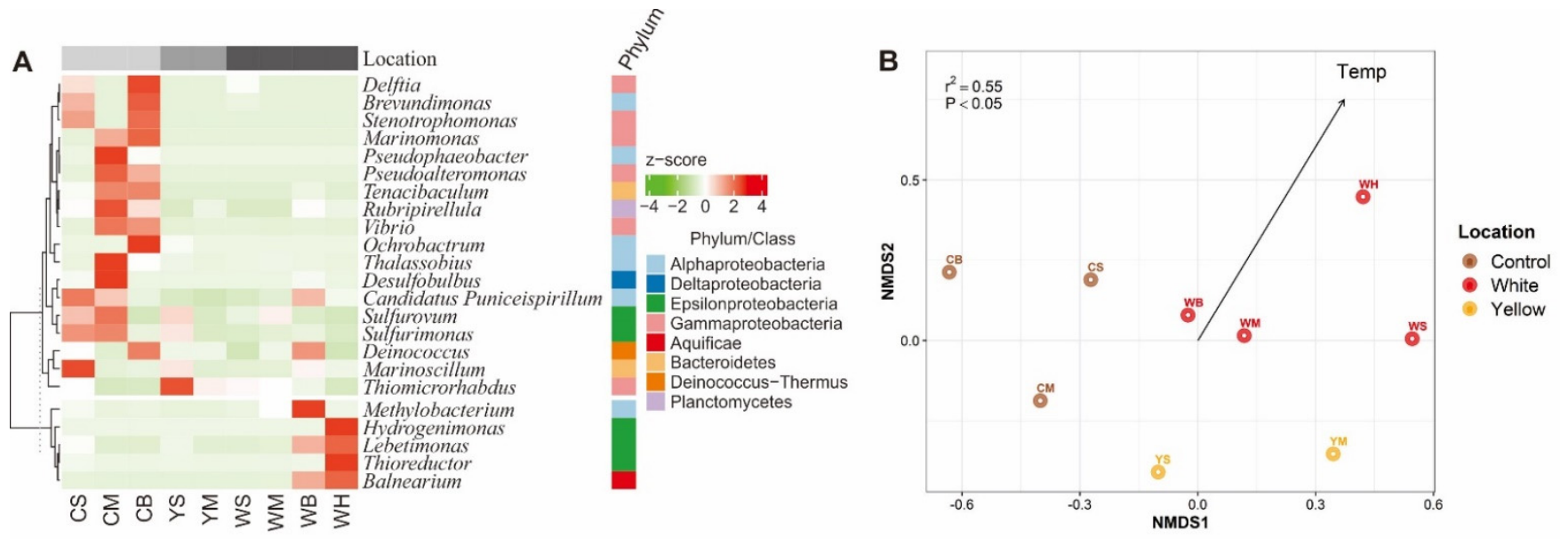

Figure 6. (A) A heatmap diagram showing the distribution of 23 dominant genera (relative abundance $>0.02 \%$ ) in the water column of the Kueishantao shallow-sea ecosystem. Each row and column of the heat map diagram corresponds to a single genus and sample, respectively. The row data (i.e., the relative abundances of genera) were z-score transformed, and then clustered based on Spearman correlation. The light gray, gray and dark gray colors in the column annotations indicate the samples from the Control site (CS, CB), White (WS, WH) and Yellow (YS, YM) vent sites, respectively. The row annotation on the right-hand side indicates the Phylum of each genus. (B) NMDS ordination showing the $\beta$-diversity pattern of the bacterial communities. Water temperature (Temp), which significantly correlate with NMDS axes $(p<0.01)$, is incorporated into plot using the 'envfit' function of the $R$ package vegan.

\subsection{Driving Forces of the ARG Profiles of the Shallow-Sea Hydrothermal Vent Ecosystem}

Previous studies have demonstrated that the HGT was the primary mechanism promoting the dissemination of ARGs in natural and anthropogenic-disturbed environments, where MGEs are the critical genetic elements mediating the HGT [11,12]. Our results indicated that the absolute abundance of ARGs had significantly positive correlation with that of MGEs in the Kueishantao shallow-sea ecosystem (Figure 7A), implying that MGEs-mediated HGT may play a certain role in enhancing the abundance of ARGs. This is consistent with the findings of many previous studies, which illustrated strong cooccurrence of ARGs and MGEs in diverse environments, such as lakes [57,58], rivers [8,59], sediments [6,18], soils [60,61], and WWTPs [15,62].

For the composition of ARGs, Procrustes analysis revealed a concordant $\beta$-diversity pattern between the bacterial communities and ARGs $\left(\mathrm{M}^{2}=0.09, p<0.001\right)$ (Figure 7B), suggesting the bacterial communities-mediated VGT processes may play an important role in shaping the composition of ARGs in the shallow-sea ecosystem. Moreover, the results of VPA analysis indicated the bacterial communities (the first axis of PCoA ordination) and physicochemical factors (salinity and $\mathrm{CH}_{4}$ ) explained 8.6 and $2.4 \%$ of the variation in the composition of ARGs, respectively (Figure 7C). Remarkably, the bacterial communities and physicochemical factors had high shared effects on the composition of ARGs (80.1\%), suggesting the environmentally structured bacterial communities controlled the $\beta$-diversity of the ARGs. However, MGEs did not show significant impacts on the composition of ARGs. Taken together, our findings suggest that the HGT and VGT might be the main processes influencing the abundance and community composition of the ARGs of the shallow-sea system, respectively. Similar results were found for the sediment ARGs of an urban coastal lagoon [19]. In addition, by using a combination of HT-qPCR and statistical analyses (i.e., Procrustes analysis and structural equation model), Chen et al. (2019) have shown that the relative importance of VGT and HGT processes could change in different habitats (i.e., water, sediments and soils) of a drinking water reservoir ecosystem [18]. However, since HT-qPCR analysis cannot provide the host information of ARGs, and determine the actual link between ARGs and MGEs, further studies based on metagenomic sequencing 
are needed to shed light on the dissemination mechanisms (i.e., HGT and VGT) of ARGs in the shallow-sea hydrothermal vent systems.
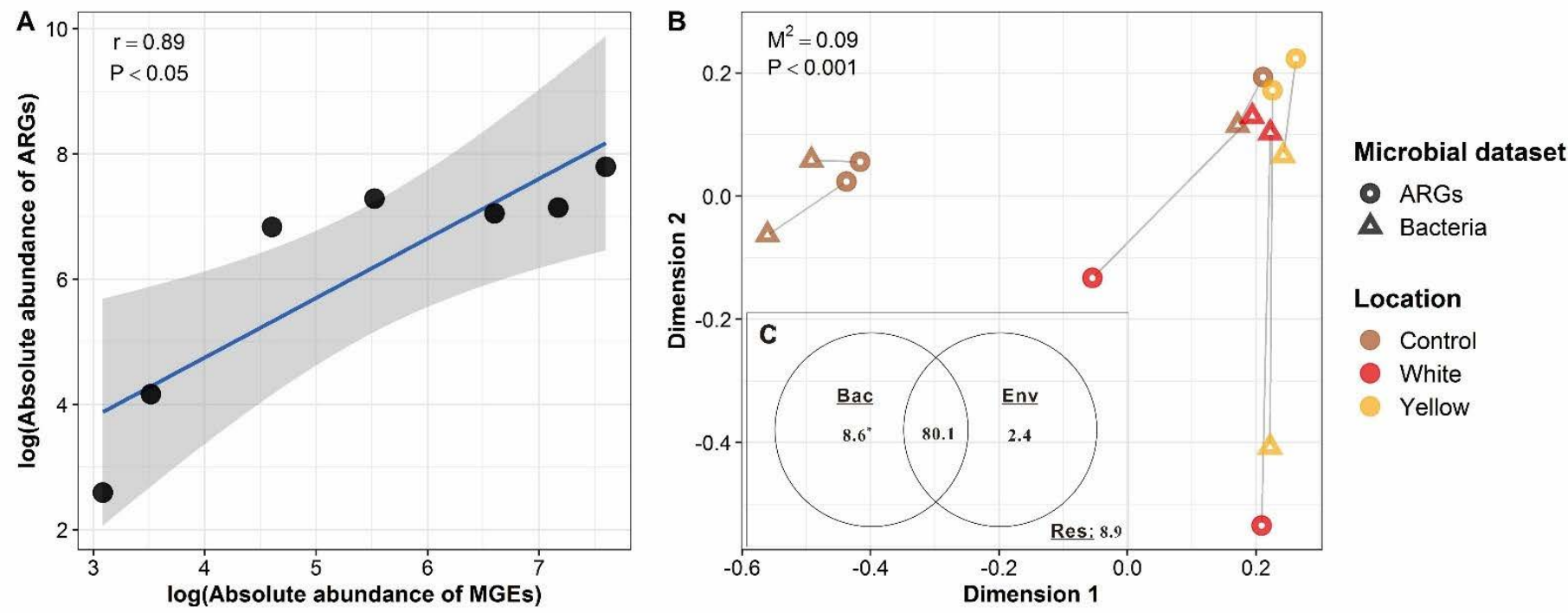

Figure 7. (A) The correlation relationship of the absolute abundances of ARGs and MGEs in the shallow-sea hydrothermal vent ecosystem; (B) Procrustes analysis showing the significant correlation between the compositions of ARGs and bacterial communities from the shallow-sea hydrothermal vent ecosystem; (C) variation partitioning analysis showing the relative impacts of the bacterial community composition (Bac), environmental variables (Env), their interactions on the $\beta$-diversity variation of ARGs. Res indicates residual variance of the model. ${ }^{*} p<0.1$.

\subsection{Implications for the Baseline Levels of Environmental ARGs}

Various lines of evidence reveal that ARGs are widespread in natural and man-made environments [63], and anthropogenic disturbances, such as sewage discharge, manure fertilization and chemical pollution, could significantly promote the proliferation and dissemination of ARGs $[12,64,65]$. McCann and colleagues demonstrated that human and wildlife disturbances resulted in 100 times higher abundance of total ARGs and MGEs in impacted than in non-impacted High Arctic soils [37]. Yang et al. (2021) found 63.6\% of ARGs in sediments of the Mariana Trench $(10,890 \mathrm{~m})$ may originate from anthropogenic pollution sources, suggesting the ARG accumulation already occurred in the deepest part of the ocean [66]. By comparing the ARG profiles among multiple pristine and anthropogenicdisturbed environments analyzed by the same technology (i.e., HT-qPCR), we found the Kueishantao shallow-sea ecosystem harbored the lowest diversity and abundance of ARGs. Although different high-throughput molecular approaches (i.e., HT-qPCR and metagenomic sequencing) have been used by this work and Yang et al. (2021), it is unexpected that similar normalized abundances of ARGs $\left(\sim 10^{-3}\right.$ copy per cell) were observed from the Kueishantao shallow-sea ecosystem and deep sea sediments [66]. These results may indeed reflect the baseline level of ARGs in pristine environments. Although the Kueishantao shallow-sea ecosystem is not located so far from the cities (e.g., Yilan) (Figure 1), the continuous influence of vent plume fluids may be helpful to keep the system as the pristine properties [32]. However, the HT-qPCR approach only target known ARG subtypes. Although the specificity and validity of the primers used here have been approved by many studies [6,8], more primers targeted novel ARG subtypes were designed and used recently [67]. Hence, our current study may underestimate the diversity and abundance of the ARGs in the shallow-sea ecosystem. In addition, due to the low detected number of ARGs, it is impossible to speculate the potential hosts of the vent ARGs by using network analysis $[6,14]$. The long-read sequencing-based metagenomic studies may address the aforementioned remaining issues in the future. 


\section{Conclusions}

In summary, this study revealed the abundance and diversity of ARGs in the shallowsea hydrothermal vent ecosystem of the Kueishantao Islet for the first time by using HT-qPCR technology. In comparison with the ARG profiles from other pristine and human-disturbed environments, we found that the Kueishantao shallow-sea system harbored the relatively low diversity (average 10 ARG subtypes) and abundance (average $1.0 \times 10^{-3}$ copy per bacterial cell) of ARGs, suggesting these ecosystems may reflect the background level of ARGs in the pristine environments. Moreover, the statistical analysis demonstrated that local environmental variables (e.g., temperature, salinity and $\mathrm{CH}_{4}$ ) and bacterial communities (e.g., thermophilic microorganisms) may be the main factors influencing the pattern of the ARGs in the shallow-sea system, implying the potential role of VGT in shaping the ARG profiles. However, considering the limits of HT-qPCR as discussed above, further studies are required to decipher the dissemination mechanisms of ARGs in the shallow-sea hydrothermal vent ecosystem.

Supplementary Materials: The following are available online at https: / /www.mdpi.com/article/ 10.3390/su14031776/su14031776/s1, Table S1: Environmental variables of the water samples from the Kueishantao shallow-sea hydrothermal vent ecosystem; Figure S1: Sampling map of 16 lakes in the Tibet plateau.

Author Contributions: Conceptualization, A.H. and Y.Z.; methodology, J.L., L.Z. and A.H.; software, J.L. and A.H.; validation, J.L. and A.H.; formal analysis, J.L. and A.H.; investigation, L.Z., Y.L. (Yufang Li), K.L., Y.L. (Yongqin Liu), S.H., F.L. and Y.Z.; resources, K.L., Y.L. (Yongqin Liu), S.H. and C.-T.A.C.; data curation, J.L., L.Z. and A.H.; writing-original draft preparation, J.L. and A.H.; writing-review and editing, Y.Z.; visualization, J.L. and A.H.; supervision, Y.Z. and A.H.; project administration, Y.Z. and A.H.; funding acquisition, Y.Z. and A.H. All authors have read and agreed to the published version of the manuscript.

Funding: This work was supported by the National Natural Science Foundation of China (U1805242), the Second Tibetan Plateau Scientific Expedition and Research Program (STEP) (2019QZKK0503) and the Youth Innovation Project of Xiamen (3502Z20206093). S. Huang thanks for the financial support from the Key Special Project for Introduced Talents Team of Southern Marine Science and Engineering Guangdong Laboratory (Guangzhou) (GML2019ZD0404).

Data Availability Statement: The datasets generated during the current study are available from the corresponding author on reasonable request.

Acknowledgments: We thank Meixian Cao for her assistance in drawing the sampling maps.

Conflicts of Interest: The authors declare no conflict of interest.

\section{References}

1. D'Costa, V.M.; King, C.E.; Kalan, L.; Morar, M.; Sung, W.W.; Schwarz, C.; Froese, D.; Zazula, G.; Calmels, F.; Debruyne, R.; et al. Antibiotic resistance is ancient. Nature 2011, 477, 457-461. [CrossRef] [PubMed]

2. Van Goethem, M.W.; Pierneef, R.; Bezuidt, O.K.I.; Van De Peer, Y.; Cowan, D.A.; Makhalanyane, T.P. A reservoir of 'historical' antibiotic resistance genes in remote pristine Antarctic soils. Microbiome 2018, 6, 40. [CrossRef] [PubMed]

3. Pruden, A.; Pei, R.; Storteboom, H.; Carlson, K. Antibiotic resistance genes as emerging contaminants studies in northern Colorado. Environ. Sci. Technol. 2006, 40, 7445-7450. [CrossRef] [PubMed]

4. Martinez, J.L.; Coque, T.M.; Baquero, F. What is a resistance gene? Ranking risk in resistomes. Nat. Rev. Microbiol. 2015, 13, 116-123. [CrossRef]

5. World Health Organization. Antimicrobial Resistance: Global Report on Surveillance; World Health Organization: Geneva, Switzerland, 2014.

6. Zhu, Y.G.; Zhao, Y.; Li, B.; Huang, C.L.; Zhang, S.Y.; Yu, S.; Chen, Y.S.; Zhang, T.; Gillings, M.R.; Su, J.Q. Continental-scale pollution of estuaries with antibiotic resistance genes. Nat. Microbiol. 2017, 2, 16270. [CrossRef]

7. Yang, Y.; Li, B.; Ju, F.; Zhang, T. Exploring variation of antibiotic resistance genes in activated sludge over a four-year period through a metagenomic approach. Environ. Sci. Technol. 2013, 47, 10197-10205. [CrossRef]

8. Hu, A.; Wang, H.; Li, J.; Mulla, S.I.; Qiu, Q.; Tang, L.; Rashid, A.; Wu, Y.; Sun, Q.; Yu, C.P. Homogeneous selection drives antibiotic resistome in two adjacent sub-watersheds, China. J. Hazard Mater. 2020, 398, 122820. [CrossRef] 
9. Pal, C.; Bengtsson-Palme, J.; Kristiansson, E.; Larsson, D.G. The structure and diversity of human, animal and environmental resistomes. Microbiome 2016, 4, 54. [CrossRef]

10. Hendriksen, R.S.; Munk, P.; Njage, P.; van Bunnik, B.; McNally, L.; Lukjancenko, O.; Roder, T.; Nieuwenhuijse, D.; Pedersen, S.K.; Kjeldgaard, J.; et al. Global monitoring of antimicrobial resistance based on metagenomics analyses of urban sewage. Nat. Commun. 2019, 10, 1124. [CrossRef]

11. Bengtsson-Palme, J.; Kristiansson, E.; Larsson, D.G.J. Environmental factors influencing the development and spread of antibiotic resistance. FEMS Microbiol. Rev. 2018, 42, fux053. [CrossRef]

12. Zhu, Y.G.; Gillings, M.; Simonet, P.; Stekel, D.; Banwart, S.; Penuelas, J. Human dissemination of genes and microorganisms in Earth's Critical Zone. Glob. Chang. Biol. 2018, 24, 1488-1499. [CrossRef] [PubMed]

13. Karkman, A.; Parnanen, K.; Larsson, D.G.J. Fecal pollution can explain antibiotic resistance gene abundances in anthropogenically impacted environments. Nat. Commun. 2019, 10, 80. [CrossRef] [PubMed]

14. Hou, L.; Wang, H.; Chen, Q.; Su, J.Q.; Gad, M.; Li, J.; Mulla, S.I.; Yu, C.P.; Hu, A. Fecal pollution mediates the dominance of stochastic assembly of antibiotic resistome in an urban lagoon (Yundang lagoon), China. J. Hazard. Mater. 2021, 417, 126083. [CrossRef] [PubMed]

15. Su, J.Q.; An, X.L.; Li, B.; Chen, Q.L.; Gillings, M.R.; Chen, H.; Zhang, T.; Zhu, Y.G. Metagenomics of urban sewage identifies an extensively shared antibiotic resistome in China. Microbiome 2017, 5, 84. [CrossRef] [PubMed]

16. Li, L.G.; Yin, X.L.; Zhang, T. Tracking antibiotic resistance gene pollution from different sources using machine-learning classification. Microbiome 2018, 6, 93. [CrossRef] [PubMed]

17. Forsberg, K.J.; Patel, S.; Gibson, M.K.; Lauber, C.L.; Knight, R.; Fierer, N.; Dantas, G. Bacterial phylogeny structures soil resistomes across habitats. Nature 2014, 509, 612-616. [CrossRef] [PubMed]

18. Chen, Y.; Li, P.; Huang, Y.; Yu, K.; Chen, H.; Cui, K.; Huang, Q.; Zhang, J.; Yew-Hoong Gin, K.; He, Y. Environmental media exert a bottleneck in driving the dynamics of antibiotic resistance genes in modern aquatic environment. Water Res. 2019, 162, 127-138. [CrossRef] [PubMed]

19. Wang, H.; Hou, L.; Liu, Y.; Liu, K.; Zhang, L.; Huang, F.; Wang, L.; Rashid, A.; Hu, A.; Yu, C.P. Horizontal and vertical gene transfer drive sediment antibiotic resistome in an urban lagoon system. J. Environ. Sci. 2021, 102, 11-23. [CrossRef]

20. Huang, J.; Zhu, J.; Liu, S.; Luo, Y.; Zhao, R.; Guo, F.; Li, B. Estuarine salinity gradient governs sedimentary bacterial community but not antibiotic resistance gene profile. Sci. Total Environ. 2022, 806, 151390. [CrossRef]

21. Li, X.; Rensing, C.; Vestergaard, G.; Arumugam, M.; Nesme, J.; Gupta, S.; Brejnrod, A.D.; Sorensen, S.J. Metagenomic evidence for co-occurrence of antibiotic, biocide and metal resistance genes in pigs. Environ. Int. 2022, 158, 106899. [CrossRef]

22. Popi, K.; Sotirios, V.; Stella, M.G.; Dimitrios, K.G.; Despo, F.K. Shotgun metagenomics assessment of the resistome, mobilome, pathogen dynamics and their ecological control modes in full-scale urban wastewater treatment plants. J. Hazard Mater. 2021, 418, 126387. [CrossRef]

23. Lee, J.; Beck, K.; Burgmann, H. Wastewater bypass is a major temporary point-source of antibiotic resistance genes and multiresistance risk factors in a Swiss river. Water Res. 2022, 208, 117827. [CrossRef] [PubMed]

24. Zhang, Y.; Zhao, Z.; Chen, C.-T.A.; Tang, K.; Su, J.; Jiao, N. Sulfur Metabolizing Microbes Dominate Microbial Communities in Andesite-Hosted Shallow-Sea Hydrothermal Systems. PLoS ONE 2012, 7, e44593. [CrossRef] [PubMed]

25. Pop Ristova, P.; Pichler, T.; Friedrich, M.W.; Buhring, S.I. Bacterial Diversity and Biogeochemistry of Two Marine Shallow-Water Hydrothermal Systems off Dominica (Lesser Antilles). Front. Microbiol. 2017, 8, 2400. [CrossRef] [PubMed]

26. Tarasov, V.G.; Gebruk, A.V.; Mironov, A.N.; Moskalev, L.I. Deep-sea and shallow-water hydrothermal vent communities: Two different phenomena? Chem. Geol. 2005, 224, 5-39. [CrossRef]

27. Tang, K.; Liu, K.; Jiao, N.; Zhang, Y.; Chen, C.T. Functional metagenomic investigations of microbial communities in a shallow-sea hydrothermal system. PLoS ONE 2013, 8, e72958. [CrossRef]

28. Rubelmann, H.; Karlen, D.J.; Garey, J.R. Changes in Eukaryotic and Bacterial Communities along a $120 \mathrm{~m}$ Transect Associated with a Shallow Marine Hydrothermal Vent. Front. Mar. Sci. 2017, 4, 177. [CrossRef]

29. Bellec, L.; Cambon-Bonavita, M.A.; Durand, L.; Aube, J.; Gayet, N.; Sandulli, R.; Brandily, C.; Zeppilli, D. Microbial Communities of the Shallow-Water Hydrothermal Vent Near Naples, Italy, and Chemosynthetic Symbionts Associated With a Free-Living Marine Nematode. Front. Microbiol. 2020, 11, 2023. [CrossRef]

30. Li, Y.; Tang, K.; Zhang, L.; Zhao, Z.; Xie, X.; Chen, C.A.; Wang, D.; Jiao, N.; Zhang, Y. Coupled Carbon, Sulfur, and Nitrogen Cycles Mediated by Microorganisms in the Water Column of a Shallow-Water Hydrothermal Ecosystem. Front. Microbiol. 2018, 9 , 2718. [CrossRef]

31. Tang, K.; Zhang, Y.; Lin, D.; Han, Y.; Chen, C.A.; Wang, D.; Lin, Y.S.; Sun, J.; Zheng, Q.; Jiao, N. Cultivation-Independent and Cultivation-Dependent Analysis of Microbes in the Shallow-Sea Hydrothermal System Off Kueishantao Island, Taiwan: Unmasking Heterotrophic Bacterial Diversity and Functional Capacity. Front. Microbiol. 2018, 9, 279. [CrossRef]

32. Lin, Y.S.; Lin, H.T.; Wang, B.S.; Huang, W.J.; Lin, L.H.; Tsai, A.Y. Intense but variable autotrophic activity in a rapidly flushed shallow-water hydrothermal plume (Kueishantao Islet, Taiwan). Geobiol. 2021, 19, 87-101. [CrossRef] [PubMed]

33. Elsaied, H.; Stokes, H.W.; Nakamura, T.; Kitamura, K.; Fuse, H.; Maruyama, A. Novel and diverse integron integrase genes and integron-like gene cassettes are prevalent in deep-sea hydrothermal vents. Environ. Microbiol. 2007, 9, 2298-2312. [CrossRef] [PubMed] 
34. Bravakos, P.; Mandalakis, M.; Nomikou, P.; Anastasiou, T.I.; Kristoffersen, J.B.; Stavroulaki, M.; Kilias, S.; Kotoulas, G.; Magoulas, A.; Polymenakou, P.N. Genomic adaptation of Pseudomonas strains to acidity and antibiotics in hydrothermal vents at Kolumbo submarine volcano, Greece. Sci. Rep. 2021, 11, 1336. [CrossRef] [PubMed]

35. Farias, P.; Espirito Santo, C.; Branco, R.; Francisco, R.; Santos, S.; Hansen, L.; Sorensen, S.; Morais, P.V. Natural hot spots for gain of multiple resistances: Arsenic and antibiotic resistances in heterotrophic, aerobic bacteria from marine hydrothermal vent fields. Appl. Environ. Microbiol. 2015, 81, 2534-2543. [CrossRef]

36. Chen, B.; Yuan, K.; Chen, X.; Yang, Y.; Zhang, T.; Wang, Y.; Luan, T.; Zou, S.; Li, X. Metagenomic Analysis Revealing Antibiotic Resistance Genes (ARGs) and Their Genetic Compartments in the Tibetan Environment. Environ. Sci. Technol. 2016, 50, 6670-6679. [CrossRef]

37. McCann, C.M.; Christgen, B.; Roberts, J.A.; Su, J.Q.; Arnold, K.E.; Gray, N.D.; Zhu, Y.G.; Graham, D.W. Understanding drivers of antibiotic resistance genes in High Arctic soil ecosystems. Environ. Int. 2019, 125, 497-504. [CrossRef]

38. Jardine, J.; Mavumengwana, V.; Ubomba-Jaswa, E. Antibiotic resistance and heavy metal tolerance in cultured bacteria from hot springs as indicators of environmental intrinsic resistance and tolerance levels. Environ. Pollut. 2019, 249, 696-702. [CrossRef]

39. Najar, I.N.; Sherpa, M.T.; Das, S.; Das, S.; Thakur, N. Diversity analysis and metagenomic insights into antibiotic and metal resistance among Himalayan hot spring bacteriobiome insinuating inherent environmental baseline levels of antibiotic and metal tolerance. J. Global Antimicrob. Resist. 2020, 21, 342-352. [CrossRef]

40. Hu, A.; Li, S.; Zhang, L.; Wang, H.; Yang, J.; Luo, Z.; Rashid, A.; Chen, S.; Huang, W.; Yu, C.P. Prokaryotic footprints in urban water ecosystems: A case study of urban landscape ponds in a coastal city, China. Environ. Pollut. 2018, 242, 1729-1739. [CrossRef]

41. Hou, L.Y.; Zhang, L.P.; Li, F.R.; Huang, S.J.; Yang, J.; Ma, C.; Zhang, D.X.; Yu, C.P.; Hu, A.Y. Urban ponds as hotspots of antibiotic resistome in the urban environment. J. Hazard. Mater. 2021, 403, 124008. [CrossRef]

42. Hu, A.; Ju, F.; Hou, L.; Li, J.; Yang, X.; Wang, H.; Mulla, S.I.; Sun, Q.; Bürgmann, H.; Yu, C.-P. Strong impact of anthropogenic contamination on the co-occurrence patterns of a riverine microbial community. Environ. Microbiol. 2017, 19, 4993-5009. [CrossRef] [PubMed]

43. Edgar, R.C. UPARSE: Highly accurate OTU sequences from microbial amplicon reads. Nat. Meth. 2013, 10, 996-998. [CrossRef] [PubMed]

44. Quast, C.; Pruesse, E.; Yilmaz, P.; Gerken, J.; Schweer, T.; Yarza, P.; Peplies, J.; Glöckner, F.O. The SILVA ribosomal RNA gene database project: Improved data processing and web-based tools. Nucleic Acids Res. 2013, 41, 590-596. [CrossRef] [PubMed]

45. McMurdie, P.J.; Holmes, S. phyloseq: An R package for reproducible interactive analysis and graphics of microbiome census data. PLoS ONE 2013, 8, e61217. [CrossRef]

46. Adyari, B.; Shen, D.; Li, S.; Zhang, L.; Rashid, A.; Sun, Q.; Hu, A.; Chen, N.; Yu, C.-P. Strong impact of micropollutants on prokaryotic communities at the horizontal but not vertical scales in a subtropical reservoir, China. Sci. Total Environ. 2020, 721, 137767. [CrossRef]

47. Oksanen, J.; Blanchet, F.G.; Kindt, R.; Legendre, P.; O’hara, R.B.; Simpson, G.L.; Solymos, P.; Stevens, M.H.H.; Wagner, H. Vegan: Community Ecology Package. R Package Version 1.17-1. Available online: http:/ /CRAN.R-project.org/package=vegan (accessed on 10 March 2010).

48. Wickham, H. ggplot2: Elegant Graphics for Data Analysis; Springer: Berlin/Heidelberg, Germany, 2016.

49. Gu, Z.G.; Eils, R.; Schlesner, M. Complex heatmaps reveal patterns and correlations in multidimensional genomic data. Bioinformatics 2016, 32, 2847-2849. [CrossRef]

50. Ma, L.; Li, B.; Jiang, X.T.; Wang, Y.L.; Xia, Y.; Li, A.D.; Zhang, T. Catalogue of antibiotic resistome and host-tracking in drinking water deciphered by a large scale survey. Microbiome 2017, 5, 154. [CrossRef]

51. Martinez, J.L. Ecology and Evolution of Chromosomal Gene Transfer between Environmental Microorganisms and Pathogens. Microbiol. Spectr. 2021, 6, 1.

52. Murdock, S.A.; Tunnicliffe, V.; Boschen-Rose, R.E.; Juniper, S.K. Emergent "core communities" of microbes, meiofauna and macrofauna at hydrothermal vents. ISME J. 2021, 1, 27. [CrossRef]

53. Lanzen, A.; Jorgensen, S.L.; Bengtsson, M.M.; Jonassen, I.; Ovreas, L.; Urich, T. Exploring the composition and diversity of microbial communities at the Jan Mayen hydrothermal vent field using RNA and DNA. FEMS Microbiol. Ecol. 2011, 77, 577-589. [CrossRef]

54. Xie, W.; Wang, F.; Guo, L.; Chen, Z.; Sievert, S.M.; Meng, J.; Huang, G.; Li, Y.; Yan, Q.; Wu, S.; et al. Comparative metagenomics of microbial communities inhabiting deep-sea hydrothermal vent chimneys with contrasting chemistries. ISME J. 2011, 5, 414-426. [CrossRef]

55. Liu, X.; Jiang, L.; Hu, Q.; Lyu, J.; Shao, Z. Thiomicrorhabdus indica sp. nov., an obligately chemolithoautotrophic, sulfur-oxidizing bacterium isolated from a deep-sea hydrothermal vent environment. Int. J. Syst. Evol. Microbiol. 2020, 70, 234-239. [CrossRef] [PubMed]

56. Nakagawa, S.; Takai, K. Deep-sea vent chemoautotrophs: Diversity, biochemistry and ecological significance. FEMS Microbiol. Ecol. 2008, 65, 1-14. [CrossRef] [PubMed]

57. Chen, H.Y.; Jing, L.J.; Yao, Z.P.; Meng, F.S.; Teng, Y.G. Prevalence, source and risk of antibiotic resistance genes in the sediments of Lake Tai (China) deciphered by metagenomic assembly: A comparison with other global lakes. Environ. Int. 2019, 127, 267-275. [CrossRef] [PubMed] 
58. Yang, Y.; Song, W.; Lin, H.; Wang, W.; Du, L.; Xing, W. Antibiotics and antibiotic resistance genes in global lakes: A review and meta-analysis. Environ. Int. 2018, 116, 60-73. [CrossRef]

59. Amos, G.C.A.; Ploumakis, S.; Zhang, L.; Hawkey, P.M.; Gaze, W.H.; Wellington, E.M.H. The widespread dissemination of integrons throughout bacterial communities in a riverine system. ISME J. 2018, 12, 681-691. [CrossRef] [PubMed]

60. Hu, H.W.; Wang, J.T.; Li, J.; Shi, X.Z.; Ma, Y.B.; Chen, D.; He, J.Z. Long-Term Nickel Contamination Increases the Occurrence of Antibiotic Resistance Genes in Agricultural Soils. Environ. Sci. Technol. 2017, 51, 790-800. [CrossRef] [PubMed]

61. Su, J.Q.; Wei, B.; Ou-Yang, W.Y.; Huang, F.Y.; Zhao, Y.; Xu, H.J.; Zhu, Y.G. Antibiotic resistome and its association with bacterial communities during sewage sludge composting. Environ. Sci. Technol. 2015, 49, 7356-7363. [CrossRef]

62. An, X.L.; Su, J.Q.; Li, B.; Ouyang, W.Y.; Zhao, Y.; Chen, Q.L.; Cui, L.; Chen, H.; Gillings, M.R.; Zhang, T.; et al. Tracking antibiotic resistome during wastewater treatment using high throughput quantitative PCR. Environ. Int. 2018, 117, 146-153. [CrossRef]

63. Bengtsson-Palme, J.; Larsson, D.G. Antibiotic resistance genes in the environment: Prioritizing risks. Nat. Rev. Microbiol. 2015, 13, 396. [CrossRef]

64. Lupo, A.; Coyne, S.; Berendonk, T.U. Origin and evolution of antibiotic resistance: The common mechanisms of emergence and spread in water bodies. Front. Microbiol. 2012, 3, 18. [CrossRef] [PubMed]

65. Manaia, C.M.; Rocha, J.; Scaccia, N.; Marano, R.; Radu, E.; Biancullo, F.; Cerqueira, F.; Fortunato, G.; Iakovides, I.C.; Zammit, I.; et al. Antibiotic resistance in wastewater treatment plants: Tackling the black box. Environ. Int. 2018, 115, 312-324. [CrossRef] [PubMed]

66. Yang, H.; Liu, R.; Liu, H.; Wang, C.; Yin, X.; Zhang, M.; Fang, J.; Zhang, T.; Ma, L. Evidence for Long-Term Anthropogenic Pollution: The Hadal Trench as a Depository and Indicator for Dissemination of Antibiotic Resistance Genes. Environ. Sci. Technol. 2021, 55, 15136-115148. [CrossRef] [PubMed]

67. Stedtfeld, R.D.; Guo, X.; Stedtfeld, T.M.; Sheng, H.; Williams, M.R.; Hauschild, K.; Gunturu, S.; Tift, L.; Wang, F.; Howe, A.; et al. Primer set 2.0 for highly parallel qPCR array targeting antibiotic resistance genes and mobile genetic elements. FEMS Microbiol. Ecol. 2018, 94, 1-8. [CrossRef] 